\title{
ZS Research Square \\ Key enzymes fuel growth and spread of breast cancer cells
}

\author{
Ya Fan \\ Wang Jia \\ Yuemei Xu \\ Yipin Wang \\ Tao Song \\ Xiubin Liang \\ Jin Feng \\ Dongming Su
}

\section{Video Byte}

Keywords: Cell Communication and Signaling, Anti-Warburg effect, Cancer progression, Molecular patterns, Treatment target, HRD1, tumor suppressor, glucose metabolism, aerobic glycolysis, regulatory signals, cancer metabolism, breast cancer, metastasis, PFKP

Posted Date: February 25th, 2021

DOI: https://doi.org/10.21203/rs.3.rs-276029/v1

License: (a) (i) This work is licensed under a Creative Commons Attribution 4.0 International License. Read Full License 


\section{Abstract}

Breast cancer is a leading cause of cancer-related death among women worldwide. One process that fuels the proliferation, survival, and migration of breast cancer cells is aerobic glycolysis. In normal cells, this conversion of glucose into lactate is normally reserved for low-oxygen conditions. Researchers have now identified a tumor-suppressing protein that helps regulate aerobic glycolysis in breast tumors. HRD1 is an enzyme known to suppress breast cancer proliferation and invasion. Experiments on human breast cancer cells clearly showed that upregulation of HRD1 decreased aerobic glycolysis. and subsequently inhibited breast cancer proliferation and invasion. This effect was found to be mediated by the enzyme PFKP. PFKP downregulation allowed HRD1 to inhibit the aerobic glycolysis and spread of breast cancer cells. These findings point to a new regulatory role for HRD1 and offer a possible target for future breast cancer therapies. 